\title{
Use of ribosomal RNA gene restriction patterns to investigate two outbreaks of campylobacter enteritis in Melbourne, Australia
}

\author{
WEE TEE, B. MAYALL*, C. R. LUCAS, R. RAYNER $\dagger$, S. PEARSON* and B. DWYER \\ Fairfield Infectious Diseases Hospital, Fairfield 3078, * Repatriation General Hospital, Heidelberg West 3081 \\ and $\uparrow$ Simpson Army Barracks, Macleod 3085, Victoria, Australia
}

\begin{abstract}
Summary. The analysis of ribosomal RNA (rRNA) gene patterns (ribotyping) has been used to differentiate strains within bacterial species. We used this method to investigate two outbreaks of campylobacter enteritis that occurred recently in Melbourne, Australia. The first outbreak involved seven patients although isolates from only five patients were available for typing. The second outbreak consisted of three patients infected with human immunodeficiency virus (HIV) on the same ward of a hospital. Analysis of the rRNA gene patterns revealed identical patterns for the isolates from five patients in the first outbreak, suggesting that these isolates were from the same source. However, ribotyping of the four isolates from the second outbreak showed three distinct ribotypes indicative of contact with unrelated sources. This study demonstrated that ribotyping is a useful, reliable and convenient typing scheme for epidemiological purposes.
\end{abstract}

\section{Introduction}

Campylobacter jejuni is the commonest bacterial cause of gastroenteritis in man in developed countries, including Australia. In England, the annual incidence of campylobacteria enteritis is approximately $50 / 100000$ people. $^{1} \mathrm{~A}$ similar incidence is observed in the USA. ${ }^{2}$ In Australia the annual incidence is not known. However, in a recent hospital-based study in Melbourne, ${ }^{3}$ we reported almost 100 cases of bacteriologically confirmed campylobacter diarrhoea/year during 1980-1984 with a prevalence rate almost equalling that of salmonella enteritis. Recent figures from annual reports (1985-1990) suggested that although the incidence of campylobacteria enteritis remained static it was almost double that of salmonella enteritis and four times that of shigella infections. Unlike salmonella infection, community-wide outbreaks of campylobacter enteritis are uncommon in Australia. Nevertheless, epidemic outbreaks of campylobacter infections associated with food, especially raw milk, ${ }^{4-8}$ and to a lesser extent undercooked poultry, ${ }^{6}$ beef $^{6,7}$ egg $^{6}$ and untreated water ${ }^{9-11}$ have been reported elsewhere.

Typing methods such as biotyping, ${ }^{12}$ serotyping, ${ }^{13,14}$ plasmid typing, ${ }^{15}$ enzyme profile analysis, ${ }^{8,16}$ restriction digest analysis, ${ }^{7,17}$ phage typing ${ }^{4}$ and most recently, ribosomal RNA (rRNA) gene pattern analysis $^{17}$ have been used to differentiate strains of $C$. jejuni for epidemiological purposes. In this study a non- radioactive Southern blot hybridisation method of rRNA gene pattern analysis was used to investigate two recent outbreaks of campylobacter enteritis in Melbourne.

\section{Materials and methods}

\section{Patients}

The first outbreak involved seven army personnel from a suburban army barracks who had gastroenteritis between 30 April and 11 June 1989. All had profuse diarrhoea and acute abdominal pain. The source of infection was not clear, but all the patients were reported to have consumed pizza from the same restaurant. $C$. jejuni was isolated from stool specimens from all seven patients. Seven other residents from the same barracks presented with gastroenteritis during this period. Five of these patients were culture-negative for $C$. jejuni and other enteric pathogens including shigella, salmonellae and Clostridium difficile. Stool specimens were not collected from two of the patients. The association of these seven patients with the suspected food source (pizza) is not clear. No attempt was made to culture campylobacters from the putative food source, nor was follow up instituted for members of staff at the pizza restaurant. Isolates from five of the seven culture-positive patients were available for typing.

The second apparent outbreak consisted of three HIV-infected in-patients of the same ward at a Melbourne hospital. One patient (the index case, Case 
A) had C. jejuni bacteraemia as well as gastroenteritis on 13 March 1991. C. jejuni was isolated from the other two cases (B and C) on 20 and 22 April respectively. Case $A$ shared a room with Case $B$ for 4 days (30 March-3 April). Case B was discharged on 3 April but was re-admitted on 18 April. During this second admission, he occupied a single room. He presented with acute abdominal pain of 1 week duration. On admission, he had watery diarrhoea that persisted for a week. Case $\mathrm{C}$, who had been in a single room on the same ward from $27 \mathrm{Feb}$. to $21 \mathrm{March}$ was transferred to a convalescent ward. He was re-admitted to the ward on 20 April, to a single room a few doors away from Case B. Copious diarrhoea was noted on 20 April. It is possible that Case B and Case $\mathrm{C}$ shared the same toilet facility. Four isolates, including the two from the blood and faecal specimens of Case A, were available for ribotyping.

\section{Isolation and identification of C. jejuni}

Stool specimens from the patients were cultured for enteric pathogens including Shigella spp. Salmonella spp. and $C$. difficile. Culture for Campylobacter spp. was on Skirrow's Medium (Oxoid) incubated at $42^{\circ} \mathrm{C}$ in a micro-aerophilic atmosphere of $\mathrm{CO}_{2} 10 \%, \mathrm{O}_{2} 6 \%$ and $\mathrm{N}_{2} 84 \%$. Colonies that showed typical morphology were identified as $C$. jejuni if they showed the following characteristics: gram-negative curved rods, motile, failure to grow in air at $37^{\circ} \mathrm{C}$, catalase- and oxidase-positive, nitrate reduction, hydrolysis of sodium hippurate, susceptibility to nalidixic acid (30 $\mu \mathrm{g}$ disk) and resistance to cephalothin (30 $\mu \mathrm{g}$ disk). Isolates were stored at $-70^{\circ} \mathrm{C}$ before typing.

\section{Extraction of chromosomal DNA}

Isolates of $C$. jejuni were removed from storage and grown on sheep blood $6 \%$ agar for 3 days at $37^{\circ} \mathrm{C}$ in micro-aerobic conditions. For each isolate, bacterial cells from three plates were suspended in $5 \mathrm{ml}$ of TrisEDTA (TE) buffer, pH 7.6. Extraction and purification of chromosomal DNA was performed as described previously. ${ }^{18}$ The concentration and purity of DNA samples were estimated by comparing the electrophoretic pattern with those displayed by a standard DNA preparation on agarose $0.7 \%$ gels.

\section{DNA probe synthesis}

Plasmid pKK 3535 was digested with restriction endonuclease PstI and labelled with digoxigenin with the non-radioactive DNA labelling and detection kit (Boehringer Mannheim, Germany) according to the manufacturer's instructions. This DNA probe derived from plasmid pB322 of Escherichia coli encodes 5S RNA, 16S RNA, 23S RNA and tRNA ${ }^{\text {Glu2 }}$ genes.

\section{Southern blot hybridisation}

Samples of DNA (c. $2 \mu \mathrm{g}$ ) were digested with 30 units each of HindIII or HaeIII restriction endo- nuclease at $37^{\circ} \mathrm{C}$ for $5 \mathrm{~h}$ under the conditions specified by the manufacturers. Excess endonuclease was used to ensure that no partial digestion products remained.

DNA fragments were separated by electrophoresis in agarose $0.7 \%$ gels at $50 \mathrm{~V}$ for $17 \mathrm{~h}$ in a buffer containing $40 \mathrm{~mm}$ Tris-acetate and $2 \mathrm{~mm}$ EDTA. The DNA fragments were transferred to a nylon filter (Gene Screen Plus, Dupont, Boston, MA, USA) with a vacuum transfer apparatus (Hybaid) at $40 \mathrm{~cm} \mathrm{H}_{2} \mathrm{O}$ vacuum for $1 \mathrm{~h}$ with $0.5 \mathrm{M} \mathrm{NaOH}, 1.5 \mathrm{M} \mathrm{NaCl}$ solution. The nylon was removed and baked at $120^{\circ} \mathrm{C}$ for $30 \mathrm{~min}$. After pre-hybridisation at $37^{\circ} \mathrm{C}$ for $2 \mathrm{~h}$ in hybridisation solution containing formamide $50 \%$, sarkosyl $0 \cdot 165 \%, \quad 5 \times$ SSC $(1 \times$ SSC is $0.15 \mathrm{M} \mathrm{NaCl}+0.015 \mathrm{M}$ sodium citrate), SDS $1 \%$ and herring sperm DNA $200 \mu \mathrm{g} / \mathrm{ml}$, heat-denatured DNA probe in hybridisation solution was added and the filter was incubated at $42^{\circ} \mathrm{C}$ overnight. After hybridisation, the filter was washed twice for 5 minutes at room temperature with $2 \times$ SSC-SDS $0.1 \%$ and twice for $30 \mathrm{~min}$ at $50^{\circ} \mathrm{C}$ with $0 \cdot 1 \times$ SSC-SDS $0 \cdot 1 \%$. The hybridisation reactions were visualised colorimetrically with the enzyme-linked immunoassay of the digoxigenin system which contains an alkaline phosphatase-conjugated antibody as described in the non-radioactive DNA labelling and detection kit (Boehringer Mannheim) and modified by using casein $1 \%$ in the blocking step and as a conjugate diluent.

\section{Results}

Chromosomal DNA from the 10 strains of $C$. jejuni (five from the first outbreak, four from the second outbreak and the type strain $C$. jejuni NCTC 11351) were digested with HaeIII or HindIII restriction endonucleases. The rRNA gene patterns (ribotyping patterns) obtained after Southern hybridisation and probing with labelled plasmid pKK 3535 are shown in

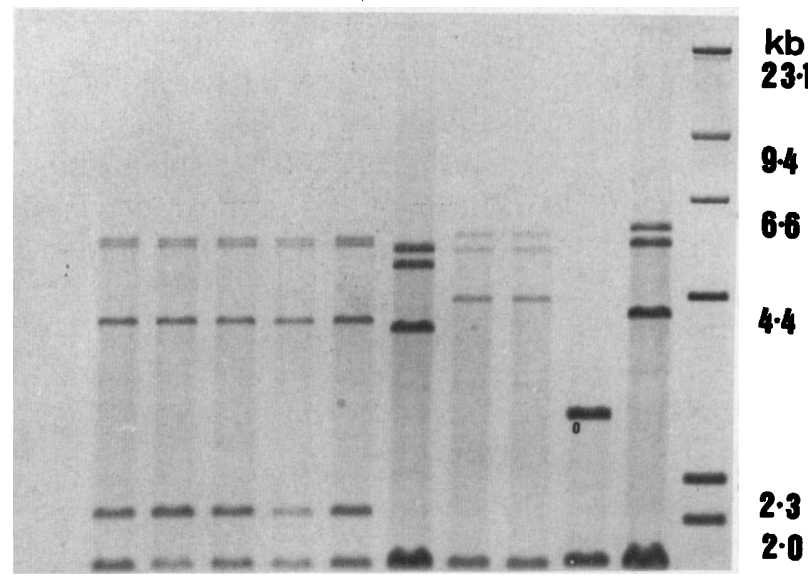

$\begin{array}{lllllllllll}1 & 2 & 3 & 4 & 5 & 6 & 7 & 8 & 9 & 10 & 11\end{array}$

Fig. 1. rRNA gene restriction patterns for HindIII digests of campylobacter DNA from two outbreaks in Melbourne. Lanes 1-5, isolates from the first outbreak (patients nos. 4516, 4519, 4520, 4518 and 4517); 6, C. jejuni NCTC $11351 ; 7-10$, strains from the second 'outbreak' (faecal and blood isolates from patient $A$, and faecal isolates from patients $B$ and $C$ respectively); 11, mol. wt marker. 


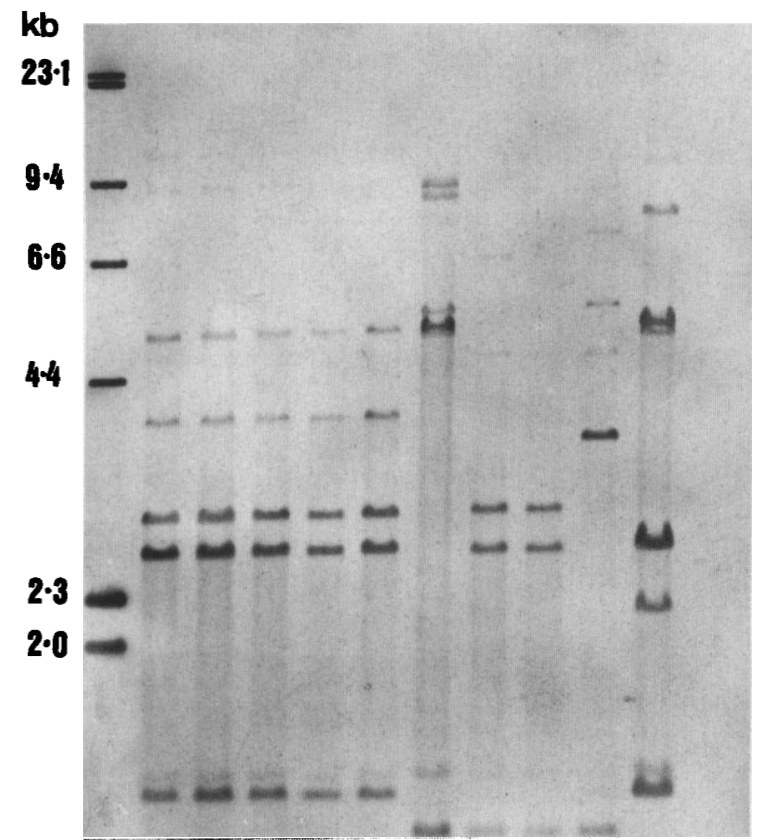

$\begin{array}{lllllllllll}1 & 2 & 3 & 4 & 5 & 6 & 7 & 8 & 9 & 10 & 11\end{array}$

Fig. 2. rRNA gene restriction patterns for HaeIII digests of campylobacter DNA from Melbourne outbreaks. Lane 1, mol. wt marker; 2-6, isolates from the first outbreak (patients nos. 4516 $4519,4520,4518$ and 4517); 7, C. jejuni NCTC $11351 ; 8-11$, strains from the second 'outbreak' (faecal and blood isolates from patient $\mathrm{A}$, and faecal isolates from patients $\mathrm{B}$ and $\mathrm{C}$ respectively).

fig. 1 (HindIII digest) and fig. 2 (HaeIII digest). Digestion with HindIII resulted in two to five bands whereas HaeIII yielded six to eight bands. Digestion with both enzymes produced clear distinct DNA bands.

Analysis of the rRNA gene patterns with either HindIII or HaeIII restriction endonuclease revealed a cluster of identical ribotyping patterns for the five patients from the first outbreak (fig.1, lanes 1-5 and fig. 2, lanes 2-6), suggesting that these isolates were genetically similar and probably from the same source. Patterns obtained with the four isolates from the three patients involved in the second outbreak showed three distinct ribotypes (fig. 1, lanes 7-10, and fig. 2 lanes $8-11$ ), indicating that the organisms were from different sources. Lanes 7 and 8 of fig. 1 are ribotyping patterns obtained with blood and faecal isolates of Case A. The identical patterns of these two isolates demonstrate that these comprise a single infecting strain. The ribotyping pattern of the type strain of $C$. jejuni NCTC 11351 was included for comparison (lane 6, fig. 1 and lane 7, fig. 2).

\section{Discussion}

The methods currently available for differentiating strains of $C$. jejuni include biotyping, ${ }^{12}$ serotyping, ${ }^{13,14}$ phage typing ${ }^{4}$, lectin typing, ${ }^{19}$ plasmid-profile analysis, ${ }^{15}$ restriction digest analysis, ${ }^{7,8,17}$ and rRNA gene pattern analysis. ${ }^{17}$ Methods that use phenotypic characteristics, such as biotyping and lectin typing, are not very useful in epidemiological studies because they are not sufficiently discriminatory. The serotyping systems of Penner and Lior have been used by some workers, ${ }^{3,8,17,20}$ but the antisera required are not available commercially. Production of antisera by individual laboratories has several drawbacks-it is time-consuming, labour-intensive and requires the use of laboratory animals.

New typing schemes have been developed recently and used successfully to distinguish strains within bacterial species. Some of these methods are very timeconsuming and require expensive laboratory equipment. For instance, enzyme profile analysis by multilocus enzyme electrophoresis takes 3 weeks or more to accomplish and requires special computer software and complicated statistical analysis. Plasmid-profile analysis can be applied only to Campylobacter strains that contain plasmids. Chromosomal DNA restriction endonuclease analysis is highly discriminatory but produces a large number of DNA bands (up to 1000 bands) rendering it impractical for typing large numbers of isolates in comparative studies. rRNA gene pattern analysis (ribotyping) generally produces between two and ten bands, and this is sufficiently discriminatory to distinguish between strains for epidemiological purposes, as has been shown in this study. The method is similar to many other molecular typing methods in complexity and cost. At present, ribotyping is relatively laborious and takes 5-6 days. It also requires specialised reagents and equipment which may be costly to set up, and hence is unsuitable for routine use in the clinical laboratory. However, it has an important place in a reference laboratory for epidemiological investigation. We found that this method, with a non-radioactive technique of Southern hybridisation, is a safe, useful and reliable typing scheme for investigating outbreaks of campylobacteriosis.

The most common outbreaks of campylobacter enteritis reported outwith Australia are generally associated with the consumption of raw or unpasteurised milk..$^{4-8}$ Drinking-water supplies ${ }^{8-11}$ have also been implicated in a few outbreaks. In Australia, epidemic outbreaks of campylobacter enteritis are uncommon, probably because it is illegal to sell or supply unpasteurised milk. Consequently, there is limited consumption of raw milk confined to individuals and isolated communities. Sporadic cases of campylobacter infections associated with consumption of food such as take-away food involving undercooked chicken, beef, seafood or pizza are common and are regularly seen in hospitals. ${ }^{3}$ However, outbreaks of campylobacter enteritis associated with food such as reported in the first outbreak in this study are rare. The organism is present in domestic animals ${ }^{20}$ and there is a high prevalence in chicken ${ }^{21}$ and other raw meat products. ${ }^{6,7}$ Thus it is not surprising that the three HIV-infected patients from the same ward acquired campylobacter enteritis co-incidentally at the same time but from different sources.

The Health Department of Victoria has recently 
introduced a new enteric disease notification system which includes campylobacter species. The ribotyping method described here provides a sensitive and reliable typing scheme, that we are currently studying to gain a better understanding of the epidemiological sig-

\section{References}

1. Skirrow MB. A demographic survey of campylobacter, salmonella and shigella infections in England. A Public Health Laboratory Service Survey. Epidemiol Infect 1987; 99: 647-657.

2. MacDonald KL, O'Leary MJ, Cohen ML et al. Escherichia coli O 157: H7, an emerging gastrointestinal pathogen: results of a one-year prospective, population-based study. JAMA 1988; 259: 3567-3570.

3. Tee W, Kaldor J, Dwyer B. Epidemiology of campylobacter diarrhoea. Med J Aust 1986; 145: 499-503.

4. Salama SM, Bolton FJ, Hutchinson DN. Application of a new phage-typing scheme to campylobacters isolated during outbreaks. Epidemiol Infect 1990; 104: 405-411.

5. Harris NV, Kimball TK, Bennett P, Johnson Y, Wakely D, Nolan CM. Campylobacter jejuni enteritis associated with raw goat's milk. Am J Epidemiol 1987; 126: 179-186.

6. Finch MJ, Blake PA. Foodborne outbreaks of campylobacteriosis: the United States experience, 1980-1982. Am J Epidemiol 1985; 122: 262-268.

7. Bradbury WC, Pearson AD, Marko MA, Congi RV, Penner JL. Investigation of a Campylobacter jejuni outbreak by serotyping and chromosomal restriction endonuclease analysis. J Clin Microbiol 1984; 19: 342-346.

8. Patton CM, Wachsmuth IK, Evins GM et al. Evaluation of 10 methods to distinguish epidemic-associated Campylobacter strains. J Clin Microbiol 1991; 29: 680-688.

9. Rautelin H, Koota K, Von Essen R, Jahkola M, Sütonen A, Kosunen TU. Waterborne Campylobacter jejuni epidemic in a Finnish hospital for rheumatic diseases. Scand J Infect Dis 1990 ; 22 : 321-326.

10. Penner JL, Pearson AD, Hennessy JN. Investigation of a waterborne outbreak of Campylobacter jejuni enteritis with a serotyping scheme based on thermostable antigens. $J$ Clin Microbiol 1983; 18: 1362-1365.

11. Vogt RL, Sours HE, Barrett T et al. Campylobacter enteritis nificance of $C$. jejuni in the human and animal population, particularly with regard to the surveillance and investigation of outbreaks of infection.

We thank the Department of Defence for permission to publish details of the cases and Mrs Trish Clark for secretarial assistance.

associated with contaminated water. Ann Intern Med 1982 96: 292-296.

12. Lior H. New, extended biotyping scheme for Campylobacter jejuni, Campylobacter coli and "Campylobacter laridis". J Clin Microbiol 1984; 20: 636-640.

13. Lior H, Woodward DL, Edgar JA, Laroche LJ, Gill P. Serotyping of Campylobacter jejuni by slide agglutination based on heat-labile antigenic factors. $J$ Clin Microbiol $1982 ; 15$ : 761-768.

14. Penner JL, Hennessy JN. Passive haemagglutination technique for serotyping Campylobacter fetus subsp. jejuni on the basis of soluble heat-stable antigens. J Clin Microbiol 1980; 12: 732-737.

15. Tenover FC, Williams S, Gordon JP, Harris N, Nolan C, Plorde JJ. Utility of plasmid finger-printing for epidemiological studies of Campylobacter jejuni infections. $J$ Infect Dis 1984; $149: 279$.

16. Elharrif Z, Megraud F. Characterization of thermophilic campylobacter. II. Enzymatic profiles. Curr Microbiol $1986 ; 13: 317-322$.

17. Owen RJ, Hernandez J, Bolton F. DNA restriction digest and ribosomal RNA gene patterns of Campylobacter jejuni: a comparison with bio-, sero-, and bacteriophage-types of United Kingdom outbreak strains. Epidemiol Infect 1990; 105L 265-275

18. Ausubel FM, Brent R, Kingston RE et al. Current protocols in molecular biology. New York, John Wiley and Sons. 1988.

19. O'Sullivan N, Benjamin J, Skirrow MB. Lectin typing of Campylobacter isolates. J Clin Pathol 1990; 43: 957-960.

20. Blaser MJ, LaForce FM, Wilson NA, Wang WLL. Reservoirs for human campylobacteriosis. $J$ Infect Dis $1980 ; 141$ : 665-669.

21. Park CE, Stankiewicz ZK, Lovett J, Hunt J, Francis DW. Effect of temperature, duration of incubation, and $\mathrm{pH}$ of environment culture on the recovery of Campylobacter jejun from eviscerated market chickens. Can J Microbiol 1983; 29: 803-806. 